\title{
Anxiety and Depression Differences Between the Nurses Working at a
}

\section{COVID-19 Pandemic Hospital}

\author{
Mehmet Tercan ${ }^{1}$, Firdevs Tuğba Bozkurt $^{2} *$, Gulçin Patmano ${ }^{3}$, Gülben Saraçoğlu ${ }^{4}$, Sibel Ceylan Gür ${ }^{5}$
}

\author{
Abstract \\ Objective: To investigate anxiety and depression differences between the nurses working at a COVID-19 pandemic \\ hospital in Turkey. \\ Material and Methods: A quantitative approach using a survey was applied. There were 331 nurses recruited by \\ convenience sampling.
}

Results: Females have higher anxiety scores at a significant level $(\mathrm{p}=0.017)$. It was also found that nurses who have family members with chronic disease have higher depression scores than nurses who do not have at a significant level $(\mathrm{p}=0.376)$. Similarly, nurses who have elderly family members have higher depression and anxiety scores than nurses who do not have at a significant level $(\mathrm{p}=0.008)$. There was a significant difference between the nurses providing and not providing COVID-19 care for depression scores $(\mathrm{p}=0.002)$.

Conclusion: This study explores nurses' depression and anxiety levels. Even though this phenomenon has already been studied, the outbreak of COVID-19 draws more attention to health workers and especially nurses who are part of the pandemic context. Nurses who provide COVID-19 care have higher depression and anxiety scores. Nurses who help patients to recover from COVID-19 should be in functional mental status. Thus, governments, health organizations, and hospital administrations should take adequate steps to reduce nurses' depression and anxiety to sustain a healthy world.

Keywords: Anxiety, depression, nurse, COVID-19, Pandemic

\section{Introduction}

The world's agenda has changed as COVID-19 (Coronavirus). The situation is almost the same all around the world. Governments are trying to keep the public at home. Meantime, health workers are working harder to stop the pandemic. Although extraordinary efforts have been made to investigate the pathophysiology, clinical consequences and treatment of coronavirus disease (COVID-19), the psychological effects of this pandemic on healthcare workers cannot be ignored. Experiences from the acute reports of acute respiratory syndrome (SARS) in 2003 and COVID-19 indicate that healthcare professionals experience anxiety, stress, and fear. Similarly, a recent interview showed that health workers providing COVID-19 care are facing a mental health crisis (1). A report published by the World Health Organization warns the health worker to be careful about not feeling under pressure and stress (2). Similarly, another WHO report also warns nations about the possible rise of the depression and loneliness on health workers (3).
The psychological effects associated with the current pandemic are due to many factors such as uncertainty about the duration of the crisis, lack of proven therapies or vaccines and potential deficiencies of health resources, including personal protective equipment. Health workers are stressed out because of the possibility of their family and friends being ill, their inability to be with their families, and the social distance rules to be followed. Healthcare professionals may experience psychological distress by providing direct care to COVID-19 patients, recognizing someone who has died or died due to this disease or by quarantine or isolation. A recent study which was conducted in Wuhan, China, shows that healthcare workers have suffered adverse psychological reactions (4).

Strategies to alleviate potential stress situations are vital for ensuring a healthy and sound clinical workforce for all scenarios (4-6). 
The purpose of this study is to investigate anxiety and depression differences between the nurses working at a COVID-19 pandemic hospital. Within the scope of this main purpose, this study aims to investigate anxiety and depression differences between the nurses for their following characteristics; providing COVID-19 care, gender, education levels, marital status, department working, using protective equipment, working hours, having COVID-19 case at home, having a chronic disease, having children, having elderly family member, having a family member with chronic disease, recently coming from abroad and contacting a COVID-19 patient.

\section{Material and Methods}

The study design and protocol was approved by Harran University Ethics Committee(27/04/2020-20.08.23). The first COVID-19 case in Turkey was identified in March 2020. The hospital where this research was carried out also served as a pandemic hospital. All sections of this hospital were divided into providing COVID-19 and not providing COVID-19. All departments of the emergency room, intensive care, laboratory, service, and radiology in the hospital were divided into sections by making necessary arrangements due to COVID-19.

This study included 331 healthcare staff (nurses) working in an education and research hospital with a bed capacity of 800 , where patients with suspected or diagnosed due to Covid-19 pandemics were also followed up and treated. Before the questionnaire was applied to the staff working in the units, verbal information was given about the study, and written consent was obtained from the participants who did not have any mental illness and agreed to participate in the study. The staff involved in all the services of the hospital on the week of the study was included in the research. The participants of this study were surveyed from March 30 to April 13, 2020.

The dependent variables of the study are the Beck Anxiety Inventory (BAI) and Beck Depression Inventory (BDI) scores. Age, gender, marital status, the number of children, educational status, presence of chronic disease, the number of people living together at home, presence of individuals with chronic disease/over 65 years of age, department, weekly working time, the status of being on duty in the services provided to the patients with possible or diagnosed Covid-19 infection, access to and use of protective equipment, the workers' methods and duration of following the pandemic process of the person were determined as the independent variables of this study.

BAI and BDI scales were used to measure depression and anxiety levels. The validity and reliability of these scales were tested in previous studies $(7,8)$. The Turkish version of the inventory was developed by Ulusoy (8).

Beck Anxiety Inventory (BAI): The inventory was determined to have sufficient reliability and validity. BAI evaluates the frequency of anxiety symptoms experienced by the individual. It is a self-assessment scale consisting of twenty-one items, and each item is scored between 0-3. With the questions asked to the patient, how much the feeling of distress disturbs him in the last week is questioned. The score range of the scale is $0-63$. The high score obtained from the scale indicates the severity of the anxiety experienced by the individual (8).

Beck Depression Inventory (BDI): This inventory was developed by Beck and colleagues (7) and adapted to Turkish by Hisli (9). This inventory is a self-assessment scale applied to healthy and psychiatric patient groups. Its purpose is to identify the risk of depression and measure the level of depressive symptoms and change in severity. This form, which includes a total of 21 self-rating scales, provides a four-point Likert-type measurement. Each item gets a gradually increasing score between 0-3, and the total score is obtained by adding them up. A high total score indicates a high severity of depression. The inventory was determined to have sufficient reliability and validity (1012).

After calculating the BDI and BAI scores, the relationship between these scores and other variables was evaluated. Beck Anxiety Inventory and Beck Depression Inventory are among the most commonly used tests that have open access $(7,13)$.

\section{Results}

The findings of this study are categorized into three sections; descriptive analysis, mean differences, and regression analysis.

The descriptive analysis shows that the average age of the participants is $28.67 \pm 5.903$ years. The average age of the nurses providing COVID-19 care is $28.58 \pm 6.323$, and not providing COVID-19 care is $28.75 \pm 5,508$. A chi-square test of goodness-of-fit was performed to determine whether providing COVID-19 care is equally distributed among nurses. Preference for two nurse groups is equally distributed in the population, $\mathrm{X} 2(2, \mathrm{~N}=331)=.680, \mathrm{p}>.05$. The number of female nurses $(56 \%)$ is higher than male nurses $(44 \%)$. Distribution for female and male is not equally distributed in the population, $\mathrm{X} 2(2, \mathrm{~N}=331)=$ $4.136, \mathrm{p}<.05$. Almost half the participants $(44 \%)$ work at the intensive care section of the hospital, however, department distribution is not equally distributed in the population, $\mathrm{X} 2(2, \mathrm{~N}=331)=295.810, \mathrm{p}<.05$. Most of the participants $(98 \%)$ accept that they can access the protective equipment for the COVID-19 cases. Only $11 \%$ of the nurses have COVID-19 cases at their home, but $89 \%$ of them do not have COVID-19 case at their home. Some of the nurses $(31 \%)$ have children, and a chi-square test of goodness-of-fit shows that having children is not equally distributed in the population, $\mathrm{X} 2(2, \mathrm{~N}=331)=47.205$, $\mathrm{p}<.05$. Only a few nurses $(5 \%)$ have elderly family members at home. However, $16 \%$ of the nurses report that they have a family member with chronic diseases. The percentage of nurses who contacted a patient with COVID19 is 1 and who has friends with COVID-19 is 6 . The chisquare test of goodness-of-fit analysis shows that having a family member with Covid-19 is not equally distributed in the population, $\mathrm{X} 2(2, \mathrm{~N}=331)=831.745, \mathrm{p}<.05$ (Table 1$)$. 
Table 1. Descriptive statistics about participants

\begin{tabular}{|c|c|c|c|c|c|}
\hline & & $\mathbf{f}$ & $\%$ & $X^{2}$ test & $\mathbf{p}$ \\
\hline \multirow[t]{2}{*}{ Sex } & Female & 184 & $56 \%$ & $4,136^{b}$ & \multirow{2}{*}{.042} \\
\hline & Male & 147 & $44 \%$ & & \\
\hline \multirow[t]{3}{*}{ Marital status } & Single & 149 & $45 \%$ & $151.293^{\mathrm{a}}$ & \multirow{3}{*}{.000} \\
\hline & Married & 176 & $53 \%$ & & \\
\hline & Divorced or Widowed & 6 & $2 \%$ & & \\
\hline \multirow[t]{2}{*}{ Education level } & High school & 49 & $15 \%$ & $164.015^{\mathrm{b}}$ & \multirow{2}{*}{.000} \\
\hline & University & 282 & $85 \%$ & & \\
\hline \multirow[t]{6}{*}{ Department } & Service & 106 & $32 \%$ & $295.810^{c}$ & \multirow{6}{*}{.000} \\
\hline & Operating room & 22 & $7 \%$ & & \\
\hline & Intensive care & 144 & $44 \%$ & & \\
\hline & Laboratory & 7 & $2 \%$ & & \\
\hline & Emergency & 45 & $14 \%$ & & \\
\hline & Radiology & 7 & $2 \%$ & & \\
\hline \multirow{2}{*}{ Providing COVID-19 care } & No & 173 & $52 \%$ & $.680^{\mathrm{b}}$ & \multirow{2}{*}{.410} \\
\hline & Yes & 158 & $48 \%$ & & \\
\hline \multirow[t]{2}{*}{ Protective equipment } & No & 7 & $2 \%$ & $303.592^{\mathrm{b}}$ & \multirow{2}{*}{.000} \\
\hline & Yes & 324 & $98 \%$ & & \\
\hline \multirow[t]{2}{*}{ Covid -19 case at home } & No & 294 & $89 \%$ & $199.544^{\mathrm{b}}$ & \multirow[b]{2}{*}{.000} \\
\hline & Yes & 37 & $11 \%$ & & \\
\hline \multirow[t]{2}{*}{ Chronic disease } & No & 300 & $91 \%$ & $492.876^{\mathrm{a}}$ & \multirow{2}{*}{.000} \\
\hline & Yes & 31 & $9 \%$ & & \\
\hline \multirow[t]{2}{*}{ Having children } & No & 228 & $69 \%$ & $47.205^{b}$ & \multirow{2}{*}{.000} \\
\hline & Yes & 103 & $31 \%$ & & \\
\hline \multirow[t]{2}{*}{ Elderly family member } & No & 315 & $95 \%$ & $270.094^{\mathrm{b}}$ & \multirow{2}{*}{.000} \\
\hline & Yes & 16 & $5 \%$ & & \\
\hline \multirow[t]{2}{*}{ Family member with chronic diseases } & No & 279 & $84 \%$ & $155.677^{b}$ & \multirow[b]{2}{*}{.000} \\
\hline & Yes & 52 & $16 \%$ & & \\
\hline \multirow[t]{2}{*}{ Recently coming from abroad } & No & 319 & $96 \%$ & $284.740^{\mathrm{b}}$ & \multirow{2}{*}{.000} \\
\hline & Yes & 12 & $4 \%$ & & \\
\hline \multirow[t]{2}{*}{ Contact a Covid-19 patient } & No & 329 & $99 \%$ & $323.048^{\mathrm{b}}$ & \multirow{2}{*}{.000} \\
\hline & Yes & 2 & $1 \%$ & & \\
\hline \multirow[t]{4}{*}{ Family member with Covid-19 } & No & 309 & $94 \%$ & $831.745^{\mathrm{d}}$ & \multirow{4}{*}{.000} \\
\hline & In family & 1 & $0 \%$ & & \\
\hline & Relative & 1 & $0 \%$ & & \\
\hline & Friend & 19 & $6 \%$ & & \\
\hline
\end{tabular}

a. 0 cells $(0,0 \%)$ have expected frequencies less than 5 . The minimum expected cell frequency is 110,3 .

b. 0 cells $(0,0 \%)$ have expected frequencies less than 5 . The minimum expected cell frequency is 165,5 .

c. 0 cells $(0,0 \%)$ have expected frequencies less than 5 . The minimum expected cell frequency is 55,2 .

d. 0 cells $(0,0 \%)$ have expected frequencies less than 5 . The minimum expected cell frequency is 82,5 .

As part of this study, the Beck Anxiety Inventory (BAI) and Beck Depression Inventory (BDI) were applied. The participants' scores for these both inventories were analyzed based on some variables. An independent t-test and ANOVA were used to test the mean differences. Based on these analyses, there was a significant difference between female and male nurses for BAI $(\mathrm{t}=5.808$, $\mathrm{p}=0.017<0.05)$, not for BDI $(\mathrm{t}=3.439, \mathrm{p}=0.065<0.05)$.

Nurses' marital status, education levels, departments, access to protective equipment, a family member with chronic disease, recently coming from abroad, or contact a COVID-19 patient is not making any significant differences neither for their BAI scores nor for their BDI scores (Table 2).
However, there are significant differences between nurses who provide COVID-19 care and do not provide COVID19 care for their BDI scores $(t=6.382, p=0.012)$. Similarly, a significant difference was found between nurses who have family members with chronic disease and who don't have family members with chronic disease for their BDI scores $(\mathrm{t}=6.107, \mathrm{p}=0.002<0.05)$. A significant difference was also found between nurses who have elderly family members and who don't have elderly family members for their BAI $(\mathrm{t}=7.062, \mathrm{p}=0.008<0.05)$ and BDI scores $(t=7.068, p=0.008<0.05)$. The ANOVA test results show that there are significant mean differences of BDI scores between nurses with the status of having a family member with COVID-19 (F=5.701, $\mathrm{p}=0.001<0.05)$ (Table 2). 
The logistic regression analysis was conducted to identify which independent variables have an impact on BAI and BDI scores. The results show that to be having a family member with COVID-19 significantly affect the BAI scores $(\mathrm{b}=2.966, \mathrm{t}(329)=3.803, \mathrm{p}<0.05$. The $\mathrm{R} 2$ value indicates that $3.9 \%$ of the total variation in the dependent variable, BAI, can be explained by the independent variable, having a family member with COVID-19.
Another regression analysis shows that following COVID19 news significantly predicted BDI scores, $(b=0.464$, $t$ $(329)=3.298, p<0.05$. The R2 value indicates that $2.9 \%$ of the total variation in BDI scores can be explained by the independent variable, following COVID-19 news (Table 3).

Table 2. Mean differences for BAI and BDI based on some variables

\begin{tabular}{|c|c|c|c|c|c|c|c|}
\hline & \multicolumn{3}{|c|}{ Beck Anxiety Inventory } & \multicolumn{3}{|c|}{ Beck Depression Inventory } \\
\hline & & $\mathbf{X} \pm \mathbf{S D}$ & $\mathbf{t} / \mathbf{F}$ & $\mathbf{p}$ & $\mathbf{x} \overrightarrow{\mathbf{x}} \pm \mathrm{SD}$ & $\mathbf{t} / \mathbf{F}$ & $\mathbf{p}$ \\
\hline \multirow[t]{2}{*}{ Sex } & Female & $11.20 \pm 10.348$ & 5.808 & .017 & $13.45 \pm 12.027$ & 3.439 & .065 \\
\hline & Male & $8.50 \pm 9.883$ & & & $11.04 \pm 11.330$ & & \\
\hline \multirow[t]{3}{*}{ Marital status } & Single & $9.97 \pm 10.813$ & .687 & .504 & $12.62 \pm 12.388$ & 1.104 & .333 \\
\hline & Married & $9.86 \pm 9.662$ & & & $11.94 \pm 11.269$ & & \\
\hline & Divorced or Widowed & $14.83 \pm 11.600$ & & & $19.00 \pm 9.466$ & & \\
\hline \multirow[t]{2}{*}{ Education level } & High school & $8.02 \pm 8.383$ & 2.166 & .142 & $13.65 \pm 12.115$ & .675 & .412 \\
\hline & University & $10.34 \pm 10.479$ & & & $12.16 \pm 11.712$ & & \\
\hline \multirow[t]{6}{*}{ Department } & Service & $11.63 \pm 10.833$ & 1.562 & .170 & $13.41 \pm 12.785$ & .835 & .526 \\
\hline & Operating room & $10.91 \pm 11.233$ & & & $12.05 \pm 10.362$ & & \\
\hline & Intensive care & $9.33 \pm 9.963$ & & & $11.89 \pm 11.041$ & & \\
\hline & Laboratory & $4.71 \pm 4.231$ & & & $4.86 \pm 7.819$ & & \\
\hline & Emergency & $9.60 \pm 9.822$ & & & $12.51 \pm 12.137$ & & \\
\hline & Radiology & $4.14 \pm 4.634$ & & & $14.57 \pm 15.317$ & & \\
\hline \multirow{2}{*}{ Covid-19 care } & No & $9.46 \pm 10.659$ & 1.025 & .312 & $10.45 \pm 10.389$ & 10.04 & .002 \\
\hline & Yes & $10.59 \pm 9.711$ & & & $14.49 \pm 12.812$ & & \\
\hline \multirow{2}{*}{ Protective equipment } & No & $14.00 \pm 13.952$ & 1.096 & .296 & $14.29 \pm 16.183$ & .188 & .665 \\
\hline & Yes & $9.91 \pm 10.134$ & & & $12.34 \pm 11.683$ & & \\
\hline \multirow{2}{*}{ Covid-19 at home } & No & $9.72 \pm 10.086$ & 2.014 & .157 & $11.80 \pm 11.067$ & 6.382 & .012 \\
\hline & Yes & $12.24 \pm 11.107$ & & & $16.95 \pm 15.748$ & & \\
\hline \multirow[t]{2}{*}{ Chronic disease } & No & $9.89 \pm 10.215$ & 2.370 & .095 & $12.12 \pm 11.400$ & 6.107 & .002 \\
\hline & Yes & $10.33 \pm 9.771$ & & & $13.67 \pm 13.379$ & & \\
\hline \multirow[t]{2}{*}{ Having children } & No & $9.94 \pm 10.348$ & .023 & .880 & $12.02 \pm 11.351$ & .686 & .408 \\
\hline & Yes & $10.13 \pm 9.973$ & & & $13.17 \pm 12.658$ & & \\
\hline \multirow[t]{2}{*}{ Elderly family member } & No & $9.67 \pm 9.865$ & 7.062 & .008 & $11.99 \pm 11.607$ & 7.068 & .008 \\
\hline & Yes & $16.56 \pm 14.546$ & & & $19.94 \pm 12.704$ & & \\
\hline \multirow{2}{*}{$\begin{array}{l}\text { Family member with } \\
\text { chronic disease }\end{array}$} & No & $9.78 \pm 9.910$ & .786 & .376 & $12.07 \pm 11.697$ & 1.230 & .268 \\
\hline & Yes & $11.15 \pm 11.775$ & & & $14.04 \pm 12.111$ & & \\
\hline \multirow{2}{*}{$\begin{array}{l}\text { Recently coming from } \\
\text { abroad }\end{array}$} & No & $10.13 \pm 10.231$ & 1.326 & .250 & $12.29 \pm 11.806$ & .470 & .493 \\
\hline & Yes & $6.67 \pm 9.670$ & & & $14.67 \pm 10.857$ & & \\
\hline \multirow{2}{*}{$\begin{array}{l}\text { Contact a Covid-19 } \\
\text { patient }\end{array}$} & No & $10.02 \pm 10.231$ & .120 & .729 & $12.41 \pm 11.791$ & .501 & .479 \\
\hline & Yes & $7.50 \pm 10.607$ & & & $6.50 \pm 3.536$ & & \\
\hline Family member with & No & $9.49 \pm 9.676$ & 5.701 & .001 & $12.12 \pm 11.659$ & 1.387 & .247 \\
\hline \multirow[t]{3}{*}{ Covid-19 } & In family & 17.00 & & & 16.00 & & \\
\hline & Relative & .00 & & & 3.00 & & \\
\hline & Friend & $18.84 \pm 14.630$ & & & $17.26 \pm 13.308$ & & \\
\hline
\end{tabular}

Table 3. Regression analysis for BAI and BDI

\begin{tabular}{lccccccccccc} 
Dependent Var. & Independent Var. & $\mathrm{B}$ & $\mathrm{Beta}$ & $\mathrm{t}$ & $\mathrm{t} . \mathrm{sig}$ & $\mathrm{R}$ & $\mathrm{R}^{2}$ & $\operatorname{Adj}^{2}$ & $\mathrm{~F}$ & $\mathrm{Sig}$ \\
BAI & $\begin{array}{c}\text { Family member } \\
\text { with Covid-19 }\end{array}$ & 2.966 & .205 & 3.803 & .000 & .205 & .042 & .039 & 14.459 & .000 \\
BDI & $\begin{array}{c}\text { Following Covid- } \\
19 \text { news }\end{array}$ & .464 & .141 & 3.298 & .001 & .179 & .032 & .029 & 10.874 & .001 \\
\hline
\end{tabular}




\section{Discussion}

Focusing on the scope of this study, several studies found that health workers are under higher risks of depression, anxiety, and stress because of their heavy workload (14). Nurses have been under more risk during the outbreak of severe diseases, and this was reported during SARS as well (15). Similarly, during the outbreak of COVID-19, health workers are at a high risk of displaying psychological issues $(16,17)$ and have more psychological distress and symptoms of mental illness (18). Meanwhile, researchers found that the psychological impact of quarantine can be wide-ranging, substantial, and can be long-lasting (5). Researchers found that anxiety could reduce the positive effects of social capital on sleep quality (19). Thus, counting the quarantine and hard working conditions, it is vital to sustaining the mental health of nurses.

This current study aimed to investigate the anxiety and depression differences between the nurses providing and not providing COVID-19 care. The results of this study show that there is a significant difference between the nurses providing and not providing COVID-19 care for depression scores. This finding supports previous studies (20-22). The nurses providing COVID-19 care have higher depression scores than the nurses not providing COVID-19 care do. These differences are similar for anxiety scores but it was not found significant at 0.05 level.

The female nurses have higher anxiety scores than the male nurse at a significant level. This finding is parallel to a previous study conducted by other studies (4,23-26). In another study, a gender difference was found significant for depression (27) as well. Even though female nurses' depression score was also higher than male nurses' depression scores, this difference was not found significant.

Different from a previous study (23), there is no significant difference between nurses' education levels BAI scores or BDI scores. There was no significant differences in nurses' marital status, access to protective equipment, a family member with chronic disease, recently coming from abroad, or contact a COVID-19 patient for none of the scores. Similar to a previous study (23), nurses working in the operation room have higher anxiety scores than nurses working at different sections of the hospital. Nevertheless, this difference is not found significant at the 0.05 level.

Nurses who have family members with chronic disease have higher depression scores than nurses who don't have at a significant level. Similarly, nurses who have an elderly family member at home have higher depression and anxiety scores than nurses who don't have at a significant level. This study also shows that having a family member with COVID-19 significantly predicted anxiety, and following COVID-19 news significantly predicted depression. A similar result was found in a study conducted for SARS (28) and in a recent study conducted for COVID-19 (25). On the other hand, it was reported that health worker feels anxiety when they have a lack of access to up-to-date information and communication (29). A study shows that health workers chose adaptive coping in response to SARS and reported low psychiatric morbidity (30). Nevertheless, the COVID-19 outbreak may require some special interventions to keep frontline health workers, especially female nurses, in good mental conditions (21). Besides, having a family member with COVID-19 and following news about COVID-19 are other variables that could cause depression and anxiety. Pandemic, such as COVID-19, requires careful health attention; therefore, nurses dealing with hard conditions should get more psychological and social support (31). Thus, news agencies have more responsibility to inform the public in an adequate way.

\section{Conclusion}

The results of this study have confirmed that female health workers have more anxiety scores. This study especially showed that female nurses have higher BAI scores (at significant level) and BDI scores. The study also showed that nurses providing COVID-19 care had higher depression scores. Female nurses who have a dominant number to provide COVID-19 care are important elements of the health system. The results also concludes that nurses dealing with hard conditions should get more psychological and social support .This support should be extended at all levels, such as news agency, government, public, and hospital administration.Acknowledgement, Funding: None.

Author's contributions: MT, FTB, GP, GS, SCG; Project design, Data Collection, Questionnaire design, Statistical Analyses FTB; Article preparation and revisions

Conflict of interest: The authors declare that they have no conflict of interest.

\section{References}

1. Law T. We Carry That Burden.' Medical Workers Fighting COVID19 Are Facing a Mental Health Crisis. 2020 April [cited 2020 April 10]; [about 2 p.]. Available from: https://time.com/5817435/covid19-mental-health-coronavirus/

2. WHO. Mental health and psychosocial considerations during the COVID-19 outbreak. 2020 March [cited 2020 March 23]; [about 1 p.]. Available from: https://www.who.int/docs/defaultsource/coronaviruse/mental-health-considerations.pdf

3. WHO. Mental health and COVID-19, 2020 April [cited 2020 April 29]; [about 2 p.]. http://www.euro.who.int/en/health-topics/healthemergencies/coronavirus-covid-19/novel-coronavirus-2019-ncovtechnical-guidance/coronavirus-disease-covid-19-outbreak-technicalguidance-europe/mental-health-and-covid-19

4. Lai J Ma S, Wang Y, et al. Factors associated with mental health outcomes among health care workers exposed to coronavirus disease 2019. JAMA Network 2020;3:e203976.

5. Brooks SK, Webster RK, Smith LE, et al. The psychological impact of quarantine and how to reduce it: rapid review of the evidence. Lancet 2020;395:912-20.

6. Styra R, Hawryluck L, Robinson S, et al. Impact on health care workers employed in high-risk areas during the Toronto SARS outbreak. J Psychosom Res. 2008;64:177-83.

7. Beck AT, Epstein N, Brown G, Steer RA An inventory for measuring clinical anxiety: Psychometric Properties. Journal of Consulting and Clinical Psychology 1988;56(6):893-7.

8. Ulusoy M, Şahin N, Erkmen H Turkish version of Beck Anxiety inventory: Psychometric Properties. Journal of Cognitive Psychotherapy: An international Cjuaterly 1998;12(2):163-72. 
9. Hisli N Beck Depresyon Envanteri’nin üniversite öğrencileri için geçerliği, güvenirliği. Türk Psikoloji Dergisi 1989;7:3-13.

10. Aydemir Ö, Köroğlu E. Psikiyatride kullanılan klinik ölçekler. Hekimler Yayın Birliği 2009;93:335-342.

11. Eren I, Şahin M, Tunç SE, Cure E, Civi II. Psychiatric symptoms and quality of life in patients with Behçet's disease. Neurol Psychiatr Brain Res 2006;13:169-74.

12. Hisli N. Beck Depresyon Envanteri’nin geçerliği üzerine bir çalışma. Türk Psikoloji Dergisi; 1988;6:118-26.

13. Beck AT, Rush AJ, Shaw BF, Emery G. Cognitive Therapy of Depression. New York: Guilford Pres. 1978;229-56.

14. Maharaj S, Lees T, Lal S. Prevalence and Risk Factors of Depression, Anxiety, and Stress in a Cohort of Australian Nurses. Int J Environ Res Public Health 2019;16(1): 61.

15. Wong TW, Yau JKY, Chan CLW, Kwong RSY, Ho SMY, Lau CC, Lau FL, Lit CH. The psychological impact of severe acute respiratory syndrome outbreak on healthcare workers in emergency departments and how they cope. European Journal of Emergency Medicine, 2005;12(1):13-19.

16. Huang Y, Zhao N. Generalized anxiety disorder, depressive symptoms and sleep quality during COVID-19 outbreak in China: a web-based cross-sectional survey. Psychiatry Res. 2020 Apr $12 ; 112954$.

17. Wu PE, Styra R, Gold WL. Mitigating the psychological effects of COVID-19 on health care workers. CMAJ. 2020 April 15; doi: 10.1503/cmaj.200519;

18. Bao Y, Sun Y, Meng S, Shi J, Lu L. 2019-nCoV epidemic: address mental health care to empower society. Lancet 2020;22(395):e37e38.

19. Xiao H, Zhang Y, Kong D, Li S, Yang N. Social capital and sleep quality in individuals who self-isolated for 14 days during the coronavirus disease 2019 (COVID-19) outbreak in January 2020 in China. Med. Sci. Monit. 2020;26:e923921

20. Ayanian JZ. Mental Health Needs of Health Care Workers Providing Frontline COVID-19 Care. JAMA Health Forum, 2020 April.

21. Li Z, Ge J, Yang M, Feng J, Qiao M, Jiang R, Bi J, Zhan G, Xu X, Wang L, Zhou Q, Zhou C, Pan Y, Liu S, Zhang H, Yang J, Zhu B, Hu Y, Hashimoto K, Jia Y, Wang H, Wang R, Liu C, Yang C. Vicarious traumatization in the general public, members, and nonmembers of medical teams aiding in COVID-19 control. Brain Behav. Immun., 2020;10(20):S30309.
22. Zhang W, Wang K, Yin L, Zhao W, Xue Q, Peng M, Min B, Tian, Q, Leng H, Du J, Chang H, Yang Y, Li W, Shangguan F, Yan T, Dong H, Han Y, Wang Y, Cosci F, Wang H. Mental Health and Psychosocial Problems of Medical Health Workers during the COVID-19 Epidemic in China Psychotherapy and Psychosomatics, 2020; DOI: $10.1159 / 000507639$.

23. Schmidt DRC, Dantas RAS, Marziale MHP. Anxiety and depression among nursing professionals who work in surgical units. Rev Esc Enferm USP. 2011;45(2):475-81.

24. Tan BYQ, Chew NWS, Lee GKH, et al. Psychological Impact of the COVID-19 Pandemic on Health Care Workers in Singapore. Annals of Internal Medicine 2020;doi:10.7326/M20-1083

25. Wang C, Pan R, Wan X, Tan Y, Xu L, Ho CS, HoIm RC. Mediate psychological responses and associated factors during the initial stage of the 2019 coronavirus disease (COVID-19) epidemic among the general population in China. Int. J. Environ. Res. Public Health, 2020;17(5):E1729.

26. Wenjuan G, Siqing P, Xinqiao L. Gender differences in depression, anxiety, and stress among college students: A longitudinal study from China. Journal of Affective Disorders 2020;263:292-300.

27. Theeke L. Carpenter RD, Mallow J, Theeke E. Gender differences in loneliness, anger, depression, self-management ability and biomarkers of chronic illness in chronically ill mid-life adults in Appalach. Applied Nursing Research 2019;45:55-62.

28. Nickell LA, Crighton EJ, Shawn Tracy C, Al-Enazy H, Bolaji Y, Hanjrah S, Hussain A, Makhlouf S, Upshur REG. Psychosocial effects of SARS on hospital staff: survey of a large tertiary care institution. CMAJ, 2004;170(5):793-798.

29. Shanafelt T, Ripp J, Trockel M. Understanding and Addressing Sources of Anxiety Among Health Care Professionals During the COVID-19 Pandemic. JAMA. 2020. doi:10.1001/jama.2020.5893.

30. Phua DH, Tang HK, Tham KY. Coping responses of emergency physicians and nurses to the 2003 severe acute respiratory syndrome outbreak. Acad Emerg Med. 2005 Apr;12(4):322-328.

31. Xiao H, Zhang Y, Kong D, Li S, Yang N. The effects of social support on sleep quality of medical staff treating patients with coronavirus disease 2019 (COVID-19) in January and February 2020 in China. Med. Sci. Monit., 2020;26:e923549. 